\title{
Reintroduzindo o sintoma: a psicanálise como obstáculo à cientificização do tratamento psíquico
}

\section{Reintroducing the symptom: psychoanalysis as an obstacle to the psychological treatment scientification}

\author{
Tiago I wasawa Neves* \\ Universidade Federal de Campina Grande - UFCG, Campina Grande, Paraíba, Brasil
}

Aryane Martins Lopes**

Faculdade Pitágoras - FAP, I patinga, Minas Gerais, Brasil

Thaiz Calais Bertges Moraes***

Faculdade Pitágoras - FAP, I patinga, Minas Gerais, Brasil

\begin{abstract}
RESUMO
O artigo retoma o sentido do sintoma pela psicanálise, objetivando criticar as propostas psicoterápicas contemporâneas que buscam fornecer um tratamento inequívoco para os problemas de ordem psíquica. É a partir do retorno a Freud que o sintoma adquire um sentido intrínseco à vida do sujeito. Este artigo discute um caso relatado por Freud, típico de neurose obsessiva, além de trabalhar os seguintes temas: os caminhos da formação do sintoma e sua relação com o recalque. A partir desses conceitos, ressalta-se a postura ética da psicanálise diante do sintoma apresentado pelo sujeito. Concluímos que o conceito psicanalítico de sintoma serve de obstáculo epistemológico à tentativa de tratar cientificamente do psiquismo.

Palavras-chave: Psicanálise, Sintoma, Obstáculo, Cientificização, Ética.
\end{abstract}

\begin{abstract}
The article takes up the meaning of the symptom through psychoanalysis, aimed at criticizing the contemporary psychotherapy theories that seek to provide a straightforward treatment goal for the problems of psychic nature. It is from the return to Freud that the symptom acquires a meaning that is intrinsic to the subject's life. This article discusses a case reported by Freud, typical of an obsessive neurosis, in addition to working with the following themes: the paths of symptom development and its relation to repression. From these concepts on, the ethical stance of psychoanalysis is emphasized before the symptoms presented by the subject. We conclude that the psychoanalytic concept of symptoms serve as the epistemological obstacle to the attempt of scientifically addressing the psyche.
\end{abstract}

Keywords: Psychoanalysis, Symptom, Obstacle, Scientification, Ethics. 


\section{A normatização cientificista do sofrimento psíquico}

Antes de tudo, não devemos confundir o que nomeamos aqui de cientificismo e o discurso da ciência. Jacques Lacan em A ciência e a verdade (1965 [1998]) afirma que o advento da ciência moderna não implica outra coisa senão a disjunção entre o saber e a verdade. A atividade científica, desde seu surgimento no século XVI com Galileu, trata da produção de um saber sempre com um caráter parcial e provisório, nunca como uma verdade pretensamente última e absoluta. Lacan ao pensar estas considerações epistemológicas a partir da leitura de Alexandre Koyré, conclui que a ciência se caracteriza pela foraclusão do problema da verdade de seu campo. Ora, é partir disso que ele pôde enunciar um de seus mais importantes aforismos: "o sujeito sobre quem operamos em psicanálise só pode ser o sujeito da ciência" (1965 [1998], p.873). Este aforismo indica que o sujeito é um efeito da matematização do mundo físico; um sujeito, a partir de então, com sua referência ontológica perdida, cuja falta de orientação na vida moderna não é possível de ser resolvida em função da tipificação dos casos na clínica.

Dessa forma, o princípio cientificista é aquele que pretende promover a sutura do sujeito sem se preocupar com as consequências epistemológicas do advento da ciência: a impossibilidade de tratarmos cientificamente do sujeito. Este princípio toma como palavra de ordem a ideia de que tudo aquilo que não for científico é desprovido de validade e sentido. Não é novidade alguma para nós que as propostas mais recentes no campo da psiquiatria e das neurociências buscam encontrar modalidades de tratamento clínico cada vez mais pautadas pelo "saber científico" em detrimento da escuta subjetiva. Mas a questão que nos importa é saber se este "saber científico" de que se trata nestas propostas é síncrono ou compatível à lógica de um mundo científico; resta, ainda, pensarmos: as propostas de cientificização do sofrimento psíquico seguem que exigência? Entrevê-se que o espírito cientificista contemporâneo se ampara no paradigma problema-solução ${ }^{1}$ objetivando ao máximo tipificar as formas de tratamento na clínica em função de marcadores biológicos e manuais estatísticos.

Seguindo esta linha de pensamento, vemos que em A era do homem sem qualidades (2005) Jacques-Alain Miller defende a tese de que vivemos a era dos valores medianos. Esta era, ao contrário dos séculos precedentes contaminados pelo espírito absoluto e universalizante dos sistemas filosóficos, caracteriza-se pelo suprimento das qualidades subjetivas em prol de unidades contáveis e comparáveis, produzindo a ideia de um "homem mediano". Como diria Miller, é a efetivação contemporânea "do significante-mestre sob sua forma mais pura, mais estúpida: o número 1" (2004, p.2). Nesse 
sentido, somos todos homens quantificáveis marcados por este 1 , em outras palavras, este 1 é aquilo que nos faz entrar na dança de um laço social cada vez mais amparado pela exigência superegóica de controle e profilaxia. É certo que em outras épocas foi possível definir o ser a partir de uma ética, de um saber absoluto; todavia, este não é definitivamente o quadro que se constrói no início deste século XXI. O referencial mítico e metafísico que outrora animara a esperança dos homens em ter garantida uma orientação ética e moral precisa, não são mais valorizados pelo "homem sem qualidades" que busca cada vez mais nos avanços tecnológicos respostas sobre a validação de um modo/estilo de vida. Não é difícil notar que a proliferação do "marketing" de produtos e tratamentos ditos psicológicos, prometendo uma melhora na qualidade de vida dos cidadãos, visa exatamente atender a demanda de uma sociedade preparada a devorar tudo aquilo que é promessa de felicidade e bem-estar ilimitados. No entanto, esta felicidade e bem-estar ilimitados só serão de fato efetivados caso haja uma filiação imaginária de todos os cidadãos à normatização do laço social. É a concretização daquilo que Miller aponta como sendo a "sociedade do medo", cujo objetivo não é outro senão a prevenção da suposta saúde do laço social: prevenção da saúde mental, prevenção contra a violência e o terrorismo, políticas governamentais de prevenção na esfera sanitária, tecnológica e ambiental, dentre outros exemplos.

Todavia, não é difícil entendermos como se constitui esta sociedade que cada dia mais acredita na ciência e no medo que se ergue contra ela. Como nos aponta Miller neste mesmo texto, ao colocar em discussão a tentativa de Quételet de promoção de uma "física do social", todo aparato estatístico de quantificação e classificação dos fenômenos sociais objetiva, antes de tudo, um padrão de normalidade/anormalidade que garante às políticas governamentais de cunho social uma abrangência declarada como sendo "para todos" ou "de todos". É a exigência de controle sobre as contingências mundanas que serve de alicerce para a propagação geral do medo. Como nos demonstrou Freud (1929 [1996]), a exigência cada vez mais severa do supereu não faz com que nossas renúncias pulsionais sejam contempladas com o bem-estar psíquico. Ao contrário, o controle que objetiva a eliminação do medo, só o faz reforçá-lo. E mais, o pretenso caráter universalizante desta política de controle e vigilância social é essencial, uma vez que a totalidade de caracteres do corpo social se reduz à ilusória média estatística. É isso o que constatamos, por exemplo, quando analisamos quais seriam os critérios adotados pelo Ministério da Saúde brasileiro para definir as prioridades no emprego dos recursos financeiros destinados a esta área. Ora, as campanhas de erradicação, combate e prevenção de inúmeras doenças se orientam mais por um saber epidemiológico do que por um saber clínico. Isso é o que podemos depreender da 
sempre eminente necessidade de revisão dos DSM's, manuais de diagnóstico estatístico que levam em conta somente a apresentação fenomenológica dos sintomas que inevitavelmente mudam com o passar do tempo.

Neste contexto de debate, não é de modo algum exaustivo ou inoportuno relançar a questão sobre o modo privilegiado de enfretamento utilizado pela civilização para lidar com os sintomas da esfera psíquica. Dessa forma, nos reportamos à psicanálise e percebemos que há tempos esta prática clínica tem uma postura diferenciada de outros saberes sobre o psiquismo, ou seja, a psicanálise se ocupa em clinicar o sintoma e não com a eliminação do mesmo. Podemos afirmar que este é o cerne daquilo que chamamos de "ética da psicanálise"; uma proposta ética na clínica é aquela que se orienta para a escuta do sujeito e interpretação do seu sintoma, ao contrário da perspectiva cientificista que concebe 0 mal-estar subjetivo como um obstáculo à homogeneidade civilizatória. Como afirma Freud (1916-1917 [1996], p.276) “[...] os sintomas neuróticos, como parapraxias e os sonhos, possuem um sentido e têm íntima conexão com as experiências do paciente". Desta maneira a psicanálise emergiu, estruturou-se e solidificou-se em direção contrária a este princípio cientificista, afirmando que o modo do inconsciente se manifestar era através dos sintomas, atos falhos e dos sonhos.

Este artigo discute sobre o sentido que o sintoma adquire na psicanálise, ressaltando os caminhos de sua formação e sua relação com o recalque. Entrevê-se que a abordagem que conferimos aqui se orienta para a definição do sintoma estritamente psicanalítico, não nos interessa de modo direto a conceitualização do sintoma pelas "simples repetições fenomenológicas da psiquiatria" (SVOLOS, 2005, p.1). Nosso objetivo é demonstrar que o conceito psicanalítico de sintoma é um obstáculo à cientificização do sujeito almejada pelas diversas práticas psicoterápicas dos dias de hoje. Mais ainda do que um simples obstáculo epistemológico, a psicanálise nos mostra que a determinação do sujeito imposta pela ideia de cidadania traz como efeito nocivo o mal-estar na contemporaneidade.

\section{A querela do sintoma}

A semiologia, ciência que analisa os signos e estuda os fenômenos da doença, tem seu termo utilizado pela medicina e pela linguística de maneiras distintas (PIMENTA; FERREIRA, 2003). A linguística tem como objeto de estudo todos os sistemas de signos linguísticos, por outro lado, na medicina a semiologia é destinada ao estudo dos sinais e sintomas das patologias. Sabemos que a medicina entende os sinais como manifestações objetivas das patologias, que podem ser 
diagnosticados sem o relato do sujeito. Nos casos clínicos construídos por Freud sobre as histéricas de sua época, percebemos que estas apresentavam sinais de uma suposta patologia, tais como as paralisias dos membros e as cegueiras. Entretanto, a partir da escuta de Freud sobre estes fenômenos clínicos, os sinais passaram a dar lugar ao sintoma, ou seja, às manifestações subjetivas. Essas manifestações subjetivas indicaram o fenômeno que servia para Freud como um signo, cuja significação não é esta encontrada na psicopatologia psiquiátrica clássica. Freud atestou isso quando afirmou com todas as letras que os sintomas neuróticos e histéricos não tinham uma causa orgânica. Este fato marca o surgimento da psicanálise, com a interpretação do sintoma enquanto signo de um mal-estar. Como salienta Pimenta e Ferreira:

\begin{abstract}
A prova da genialidade freudiana está na capacidade de perceber a natureza radicalmente diversa do sintoma neurótico. A anatomia histérica é diversa da anatomia orgânica. A conceituação do recalque, do inconsciente enquanto sistema, das pulsões e seus destinos, proporciona a Freud a condição de elaborar a teoria psicanalítica, a fim de dar conta deste outro espaço, desta outra cena, da dimensão fantasmática e, assim, captar e decifrar as mensagens contidas nos sintomas neuróticos. Contrariamente ao sintoma médico, sinal de doença e que deve ser eliminado, o sintoma psíquico, sinal de moléstia, de mal-estar, de conflito, de um desejo recalcado, deve ser acolhido e decifrado (PIMENTA; FERREIRA, 2003).
\end{abstract}

E mais, segundo Quinet,

se o sintoma para psicanálise é um significante, ele não deixa de ser também um signo, ou seja, uma cifra de gozo. O real do sintoma como signo é o fogo da fumaça do sujeito - lá onde há sintoma há sujeito, um sujeito como resposta do real (QUINET, 2000, p.144).

Assim, percebe-se que o interesse da psicanálise pela semiologia, está na medida em que o sintoma surge como signo de um inconsciente estruturado como uma linguagem. Como ressalta Lacan (1972-1973 [1985], p.25) "um dia percebi que era difícil não entrar na linguística a partir do momento em que o inconsciente estava descoberto". Diante desta afirmação de Lacan, ao postular a tese do inconsciente estruturado como linguagem, ele deixa claro que um sintoma diz sempre mais do que parece dizer; a começar pelo fato de que o sujeito pode dizer algo totalmente diferente do que se encontra inicialmente no nível de seu enunciado. Lacan nos ensina que o significado e o significante são dois conceitos distintos, separadas pela barra que resiste à significação. Logo, o significado passa a ser um produto do deslizamento dos significantes em uma cadeia. Há 
uma autonomia do significante em relação ao significado, e esta autonomia é o que permite as substituições presentes na metáfora e na metonímia. "O sujeito está conectado com a cadeia significante através do sintoma considerado como um significante. [...] o sujeito nada mais é do que essa representação sintomática dentro da cadeia dos significantes" (QUINET, 2000, p.131). Contudo, a tese que projeta o sintoma enquanto signo do inconsciente estruturado como uma linguagem não é a palavra final da psicanálise. Sabemos que a partir do momento da descoberta freudiana daquilo que se constitui como "além do princípio do prazer" o sintoma não é apenas signo de uma interpretação, mas sim de uma satisfação.

Sendo o sintoma uma manifestação subjetiva, será o sofrimento que este implica o motivo pelo qual o sujeito busca uma solução para o mesmo? Como afirma Quinet (2000, p. 131) "em suma, a primeira coisa a constatar é que sintoma tem um sentido. E é isso que, ao ser constatado, leva alguém a procurar saber qual é o seu sentido". É válido lembrarmos que este sentido colocado em ação pela análise não é o a priori das apresentações epidemiológicas e fenomenológicas dos manuais psiquiátricos. Segundo Svolos (2005, p.2) é a retificação subjetiva que "abre os caminhos nos quais a subjetividade do analisando está implicada - podemos até dizer de forma causal justamente nas situações que eram apresentadas inicialmente como externas a eles". O que podemos constatar na contemporaneidade, é que muitos profissionais do campo psi quando se deparam com o sintoma apresentado pelo sujeito, buscam aniquilá-lo, não se atendo à dimensão ética pela qual o sintoma se manifesta. Isso significa que as vastas propostas psicoterápicas contemporâneas que anunciam ao mundo um modo de tratamento cada vez mais respaldado pela ciência, além da atual proposta no campo da saúde mental que joga insistentemente com a possibilidade de definir uma norma comum, não se comprometem com a experiência que a psicanálise revela, isto é, "de que há um ponto que não pode ser resolvido [resorbé] e que o fato de que, finalmente, cada um só acredita profundamente no seu sintoma. [...] é por isso que o sintoma não se reduz à psicopatologia" (LAURENT, 2011, p.52). Nesse sentido, torna-se necessário apontarmos resumidamente os saberes que se ocupam da psique para entendermos como a atitude de sutura do sujeito e de credulidade na normalidade se coloca. Veremos que a psicanálise se coloca como um obstáculo à esta atitude psicológica e médica.

Para a psicologia de modo geral, o sintoma sempre se apresenta como um discurso lógico e racional; lógica dos fenômenos da vida mental que inclui os processos conscientes como primado lógico. Sabemos que etimologicamente a palavra psicologia deriva da junção de duas palavras gregas, psyche (alma) e logos (razão, discurso lógico ou racional). Em suas mais diversas linhas de abordagem, a psicologia através desta razão cientificista, visa buscar eliminar os 
sintomas e promover a saúde mental ao maior número possível de sujeitos. Podemos citar aqui a psicologia de cunho comportamental, que desde sua origem, tem se ocupado em eliminar os sintomas. Como afirmam Kaplan e Sadock:

\begin{abstract}
Ela requer menos tempo que outras terapias e não é tão cara para administrar. Embora útil para os sintomas comportamentais circunscritos, o método não pode tratar áreas globais de disfunção (p.ex., conflitos neuróticos, transtornos da personalidade). Houve e há controvérsia de Eysenck: 'A teoria da aprendizagem considera sintomas neuróticos simplesmente como hábitos aprendidos; não há neurose por trás dos sintomas, só o próprio sintoma. Livrese do sintoma e terá eliminado a neurose' (KAPLAN; SADOCK; 1990 p.1016).
\end{abstract}

Não é difícil percebermos que a psicologia comportamental se encontra numa zona muito próxima de confluência com o saber psiquiátrico clássico. O termo psiquiatria deriva do Grego e quer dizer "arte de curar a alma". Para este campo do saber, o sintoma tem um sentido e ocupa um lugar, mas compete ao psiquiatra dar a sua significação. Aqui o discurso médico não é compatível com o discurso da linguística, mas antes, com o discurso do mestre. Este discurso é reconhecido como um querer dominar, ou seja, um discurso modelo de toda relação social estabelecida pela palavra. Assim, neste contexto, percebe-se que, sumariamente, quando o saber psiquiátrico se dirige ao sujeito atua sobre este não lhe interrogando sobre seu mal, mas antes, exercendo o poder prévio de um conhecimento já estabelecido. O discurso do mestre apresenta um saber consumado, seu princípio é que tudo deve submeter-se às ditas leis da ciência. Assim, inicialmente para o mestre, o que importa é que a lei seja mantida na sua palavra de ordem. Para a psiquiatria organicista, assim como para os terapeutas cognitivo-comportamentais, o sintoma é a essência da patologia e deve ser eliminado, uma vez que todo índice de sintomatologia, seja ele orgânico ou comportamental, será encarado como um déficit de saúde, sendo tarefa primordial do médico restaurar um suposto quadro de saúde normativa. Não é nossa pretensão neste artigo nos atermos a esta discussão, mas basta nos reportarmos à Canguilhem (2009) para entendermos que $\theta$ essa perspectiva médico-clínica citada acima concebe a patologia como uma variação quantitativa dos fenômenos fisiológicos normais correspondentes. "Semanticamente, o patológico é designado a partir do normal, não como a ou dis, mas como hiper ou hipo" (CANGUILHEM, 2009, p.12). O problema é que o ideal de normalidade de funcionamento de um organismo não diz respeito à sua própria biologia ou genética, mas antes, ao desejo médico de dominar a doença, conhecendo as relações que esta estabelece com o 
estado normal que o sujeito demanda restaurar, uma vez que o amor à vida não pode ser negligenciado. Podemos dizer que este é o cerne do discurso de mestria que impera nos domínios da medicina: um saber de domínio sobre o mal-estar das pessoas. E é neste momento da discussão que é importante lembrar uma relevante tese de Lacan segunda a qual o avesso da psicanálise é o discurso do mestre (LACAN, 1969-1970 [1992]).

Ainda de acordo com Kaplan e Sadock (1990, p. 306), no manual estatístico organizado por eles, poderemos encontrar "mais de 350 termos usados para descrever os sinais e os sintomas de doenças psiquiátricas". Assim, a psiquiatria comportamental com sua descrição e classificação que se respalda pelos manuais DSM-IV e CID-10, enquadra o sujeito entre estes mais de 350 termos, classificando e diagnosticando-o; considerando os sintomas como sinal de um distúrbio orgânico, isto é, sintomas subjetivos são sinônimos, em última instância, de patologia cerebral ou desajustamento social.

Seguindo uma proposta contrária a estes saberes, a psicanálise nos ensina que o sintoma é um significante, porém, não com o significado puramente patológico; é um signo, mas não necessariamente de doença. Para Freud, desde os primórdios de seus trabalhos, o sintoma se dirige para outra cena, conceitualização decisiva que exigiu a redefinição deste. A psicanálise, neste sentido, se interessou pelo mal-estar do sujeito, pelo sintoma como resultado de um conflito psíquico inconsciente, pelo retorno dos desejos recalcados, os quais devem ser interpretados para que ocorra a decifração do enigma que os sintomas psíquicos colocam.

A partir destas afirmações, fica evidente que o sintoma é para psiquiatria e também para algumas linhas de abordagem da psicologia um signo "fechado" que aprisiona um significado (patologia) a um significante (fenômeno), enquanto que para a psicanálise, o sintoma é um signo estruturado como metáfora, ou seja, um significante que vem no lugar do outro significante. Por esta razão Freud sugeriu uma interpretação do desejo inconsciente. Sendo assim, o sintoma psicanalítico não é aquele que somente faz com que o sujeito procure um tratamento, assim declara Quinet (2000, p.145): "o sintoma de entrada corresponde ao sintoma em sua dimensão subjetiva, de divisão do sujeito, mensagem a ser decifrada, enigma que embute um sentido a ser buscado".

Dito isso, percebe-se que o sintoma se manifesta para o sujeito como uma mensagem enigmática cujo significado deve ser decifrado. 0 analista, assim, ocupa este lugar, lugar atópico do sujeito do suposto saber, aquele em que o analisado acredita ser detentor de um saber que possa eliminar o seu mal. O lugar de sujeito suposto saber aqui, não é a pessoa do analista, mas um efeito do discurso e um lugar inconsciente, simbólico que o analista é chamado a ocupar. Fica claro 
que no discurso do mestre trata-se de um sujeito que sabe, e não de um sujeito suposto saber, o qual é particular ao discurso da psicanálise.

\section{0 sentido do sintoma}

Em O Sentido dos Sintomas (1916-1917a [1996]) Freud estabelece a relação desse sentido com a vida íntima do sujeito. Ele relata nesta conferência o sentido de dois sintomas de neurose obsessiva, entre um deles, o caso de uma senhora de trinta anos de idade, submetida a uma compulsão-obsessiva de ficar correndo de um quarto para o outro chamando a empregada.

A jovem senhora, estando no quarto de sua residência, saía correndo para um quarto ao lado e retornava ao seu colocando-se em frente a uma mesa forrada por uma toalha que tinha uma grande mancha. Em seguida tocava a campainha chamando a empregada, dava-Ihe um recado ou a dispensava sem maiores explicações; logo tornava a repetir todo esse processo. Freud considerou este comportamento um ato sintomático. E a questão era qual o sentido que esta mulher dava a este ato? Segundo Freud (1916-1917a [1996], p.269) "sempre que eu perguntava à paciente. 'Por que faz isto? Qual o sentido disto?' ela respondia: 'Não sei'”. Porém, pela análise, percebeu-se o sentido do sintoma, no caso a repetição da cena que havia ocorrido na noite de núpcias dessa senhora.

Há dez anos ela se casara com um homem de muito mais idade. $\mathrm{Na}$ noite de núpcias os dois dormiram em quartos separados, um do lado do outro. Porém, para sua surpresa, ele não conseguira consumar o ato sexual. Essa cena se repete a noite toda, o marido indo de um quarto a outro, tentando sem sucesso. Assim, durante a noite 0 marido confessara ter vergonha da empregada que no dia seguinte faria a cama e não encontraria manchas de sangue como prova do ato consumado. Sendo assim, ele pega um tinteiro e derrama sobre o lençol, mas não no lugar exato que a mancha deveria ficar, revelando, segundo Freud, sua impotência.

Contudo, o que se observa é que a paciente repete a cena de sua noite de núpcias, porém no lugar do marido, quando corre de um quarto ao outro. Neste ato compulsivo, ela chama a empregada e faz com que a mesma possa ver a mancha que remete a consumação do ato sexual pelo marido, "corrigindo" a cena da noite de núpcias. Como afirmou Freud (1916-1917a [1996], p. 271) "o mais profundo segredo de sua doença consistia em que, através desta doença, protegia seu marido de comentários maldosos, justificava-se por estar separada dele e possibilitava-Ihe levar uma vida separada cômoda". Uma relação de compromisso é aí estabelecida: a jovem senhora produz o sintoma como forma de não se haver com a 
impotência do marido, já que o sintoma neurótico se apresenta como o retorno do recalcado. O sintoma da jovem senhora aqui é a reminiscência desse desencontro sexual, é o retorno da verdade - a verdade do sintoma, através da compulsão-obsessiva de que não houve relação sexual. E mais, o ato sintomático vinha para preencher, para substituir a relação sexual que não acontecera. Quinet retoma este caso freudiano e argumenta que o sentido do sintoma pode ser aprendido pelo menos de duas maneiras:

1. O sentido significante. Como no exemplo acima, o sentido do ato sintomático da obsessiva freudiana é a cena da noite de núpcias: a primeira cena dá o sentido à segunda cena. Chamemos de $S_{1}$ a noite de núpcias, de $S_{2}$ o ato sintomático e verificamos como uma cena se conecta com a outra produzindo o sentido.

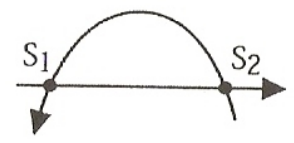

2. Em termos libidinais, o sentido do sintoma é um sentido de gozo (joui-sens). O sentido do sintoma é o real que comporta o impossível de se escrever a relação sexual. O sentido do sintoma é esse real, como estudaremos a seguir, pois o sentido, do sentido no final das contas, é que ele vaza como tonel da Danaides. O sentido está sempre vazando, escapando, pois, ao se chegar a ele percebe-se que é furado. Em ultima instancia, o sentido do sintoma é o real do gozo como aquilo que não pode ser escrito. (QUINET, 2000, p.134).

Fica assim evidente o que Freud já anunciara: o sintoma tem um sentido intrínseco à fala de um sujeito. O sintoma é este retorno do material que percorre caminho distinto ao da força que objetiva manter o recalque, em suma, uma dupla exigência se efetiva na formação do sintoma: a exigência de censura do material inconsciente e a exigência de satisfação que comporta toda e qualquer pulsão. O sintoma não é outra coisa senão o resultado desse conflito psíquico onde o eu pretende resguardar-se do desprazer por um lado, e a pulsão que exige satisfação a qualquer custo de outro lado. Portanto, a formação de um sintoma visa contemplar os dois lados deste conflito, porém, de uma forma não eficaz, já que ele será fonte de sofrimento para o sujeito que não reconhece a satisfação proposta pelo sintoma.

Já sabemos que os sintomas neuróticos são resultado de um conflito, e que este surge em virtude de um novo método de satisfazer a libido. As duas forças que entram em luta encontram-se novamente no sintoma e se reconciliam, por assim dizer, através do acordo representado pelo sintoma formado. É por essa razão, também, que o sintoma é tão 
resistente: é apoiado por ambas as partes em luta. (FREUD, 1916-1917b [1996], p. 361).

A partir de então, compreende-se que os sintomas, assim como os sonhos, são a realização de um desejo inconsciente. Em A interpretação dos sonhos (1900 [1996]) Freud deixa claro que os sintomas aparecem de maneira distorcida e disfarçada, como o fragmento do caso da jovem senhora aqui relatado, o ato sintomático diante à mesa com a empregada viera revelar os problemas enfrentados na noite de núpcias. É notável que tanto Freud quanto Lacan afirmaram que o sentido do sintoma está sempre escapando em análise, pois algo resta após sua interpretação. A este resto Lacan deu o nome de gozo, passando a entender o sintoma não somente como uma mensagem a ser decifrada, mas como uma maneira do sujeito se haver com o seu sofrimento. É o que afirma Lacan a respeito da compulsão a repetição e aqui observado no caso da jovem senhora: "repetição tem uma certa relação com aquilo que, desse saber, é o limite - e que se chama gozo" (1969-1970 [1992], p. 13). Assim a satisfação que a jovem senhora obtivera na repetição se dava no encontro faltoso com o real. Essa satisfação apontara para o real, para o impossível de se escrever. "Assim, o sintoma emerge como um derivado múltiplas-vezes-distorcido da realização de desejo libinal inconsciente, uma peça de ambiguidade engenhosamente escolhida, com dois significados em completa contradição mútua" (FREUD, 1916-1917b [1996], p. 363).

O sintoma aparece assim como uma satisfação do desejo inconsciente distorcido e disfarçado, da qual a função é conciliar forças mutuamente contraditórias, pois, atende ao Eu, mas também não deixa de responder ao Isso. Sendo assim, a satisfação que o sintoma consegue tem muitas vezes um sentido estranho para o sujeito.

Sabemos que o recalque é um dos destinos que uma pulsão pode sofrer no intuito de torná-la inoperante. Freud nos diz que o recalque só ocorre quando se estabeleceu uma cisão entre a consciência e o inconsciente, uma vez que sua finalidade seria manter alguns conteúdos da mente em estado inconscientes. Para que haja recalque é necessário pensarmos que atingir a finalidade da pulsão traria desprazer ao invés de prazer. Freud apresenta a existência de duas fases do recalque; a primeira que consiste em negar entrada no consciente ao representante psíquico da pulsão, estabelecendo a fixação, que serve como força de atração dos conteúdos ideacionais para o inconsciente e, posteriormente, a segunda fase do recalque, a propriamente dita, que afetaria todos os outros representantes ideacionais que tenham entrado em ligação associativa com o primeiro representante recalcado, servindo como uma força que tende a afastar esses conteúdos da consciência. Em seguida, Freud (1915a [1996], p.154) afirma "na verdade, o recalque só interfere na 
relação do representante pulsional com um único sistema psíquico, a saber, o do consciente".

O recalque consiste na tentativa do Eu se furtar do desprazer, mas este mecanismo é falho, não poupa o sujeito do desprazer, como prova a formação dos sintomas. Segundo Freud, se o recalque não conseguir impedir sentimentos de desprazer e angustia, pode-se dizer que falhou. O recalque é por definição um destino pulsional marcado pela falha, pois no decorrer dos acontecimentos seu fracasso se torna cada vez mais acentuado, pois o recalcado consegue retornar, só que de forma transformada e disfarçada, dando origem aos sintomas. É apenas desse recalque falho que temos notícias, porque algo escapa à tentativa imperativa do Princípio do Prazer. Desta maneira percebemos que se tais conteúdos psíquicos aparecem, há de se supor que trazem consigo desprazer, o que implica em que o recalque não tenha sido totalmente bem sucedido em afastar essa possibilidade do desprazer.

Inicialmente foi a partir do discurso da histérica que Freud pôde demonstrar que o sintoma tem um sentido, um sentido inconsciente, ou seja, o sintoma diz alguma coisa, mesmo que o sujeito nada saiba disso. E não somente diz, mas também serve a um fim de satisfação, uma "satisfação real", reconhecida pelo sujeito como um sofrimento. O sintoma é o lugar paradoxal onde o sujeito, sem que ele o saiba, tem a sua satisfação pulsional e, também, o seu sofrimento. 0 sofrimento está diretamente relacionado aos grandes dispêndios mentais necessários para se lutar contra eles.

$\mathrm{Na}$ clínica psicanalítica, o sintoma é entendido como um fenômeno subjetivo que não se constitui como um sinal de doença, mas como resultado de um conflito inconsciente. É fato que o sintoma é importante, ele possui um motivo e um propósito para existir e também possui causa, direção e finalidade na vida psíquica.

A psiquiatria clínica atenta pouco para a forma externa do conteúdo dos sintomas individualmente considerados, que a psicanálise, entretanto, valoriza precisamente este ponto e estabeleceu, em primeiro lugar, que os sintomas têm um sentido e se relacionam com as experiências do paciente. (FREUD, 1916-1917a [1996], p. 265).

Desta forma compreende-se que o sintoma é uma expressão atrapalhada de uma verdade inscrita no inconsciente, sendo tarefa do trabalho analítico interpretá-la. É importante, então, destacarmos que para a psicanálise o sintoma revela não a verdade da doença, mas a verdade do sujeito do inconsciente, pois busca apreender no sintoma o desejo inconsciente indestrutível, do qual fala Freud em A interpretação de sonhos (1900 [1996]). A clínica psicanalítica considera o sintoma como aquilo que incomoda, provoca desprazer, causa dor, motivando as pessoas a procurarem uma análise e a 
tentarem entender a causa deste tratamento. Mas o sintoma não é só patológico, não é apenas fonte de sofrimento, mas pode ser uma saída na saúde que garanta certa ordem no sujeito. Sua formação é necessária e inevitável para o funcionamento do psiquismo.

Desta maneira, a clínica psicanalítica não objetiva a eliminação do sintoma, pois a questão que se coloca diz respeito à etiologia, ao enigma que ele representa, para então implicar uma mudança da relação do sujeito com seu gozo. Assim o tratamento psicanalítico propõe, dentro das possibilidades de cada caso, a construção de um novo equilíbrio pulsional.

Em 1920, Freud reorganizou seu dualismo pulsional a partir do conceito de pulsão de morte e propôs um novo dualismo: pulsão de vida versus pulsão de morte. Com esta descoberta, pôde concluir que o fim último do homem já não era necessariamente o bem e a felicidade, mas a satisfação. Esta é a grande virada proposta pela psicanálise na discussão ética. Freud observou que o homem não buscara necessariamente o bem e o que é bom, mas a satisfação, que podia vir de forma muito diferente do que os princípios morais em questão julgavam enquanto justas. Assim, para Freud o sintoma, neste momento de sua obra, já não é apenas mensagem de um desejo recalcado, mas é também o lugar de uma satisfação mórbida, onde o sujeito se satisfaz com aquilo que o faz sofrer. Eis a questão ética: o que fazer diante do sintoma do sujeito? Esta questão é crucial para o problema que colocamos neste artigo, tal como nos alerta Laurent (2011, p.50) ao lançar questão: "será que vamos explicar o savoir faire segundo o qual o sintoma poderá entrar no laço social? Iremos nos contentar, por outro lado, a mostrar que o sintoma faz obstáculo ao laço social". E ainda, que outra conclusão a psicanálise nos revela senão a de que o laço social é um semblante? A ética psicanalítica se pauta em não obedecer à exigência de adequação à norma social, mas implica uma mudança da relação do sujeito com seu gozo. Portanto, o sentido de cura para a psicanálise não é o mesmo daquele encontrado no discurso médico. É o que pontua Násio (1999, p. 160) ao afirmar que “[...] não existe conceito psicanalítico de cura, e que esta não pode ser uma finalidade que o analista deva perseguir na sua prática, como acontece na medicina". A psicanálise, assim, surge da neurologia para logo em seguida romper com ela. A vontade desenfreada em curar o sujeito eliminando os sintomas é, na visão de Freud, um fanatismo, como atesta esta passagem abaixo:

Para muitos casos, eles são suficientes e, quando tudo está dito, a sociedade humana não tem mais uso para o furor senandi do que para qualquer outro fanatismo. Mas acreditar que as neuroses podem ser vencidas pela administração de remediozinhos inócuos é subestimar grosseiramente esses distúrbios, tanto quanto à sua origem 
quanto à sua importância prática. Não; na clínica médica sempre haverá lugar para o 'ferrum' e para o 'ignis', lado a lado com as 'medicinas'; e, da mesma maneira, nunca seremos capazes de passar sem uma psicanálise estritamente regular e forte, que não tenha medo de manejar os mais perigosos impulsos mentais e de obter domínio sobre eles, em benefício do paciente. (FREUD, 1915b [1996], p. 188).

Esta afirmação deixa claro que a ética psicanalítica é a ética do desejo, a ética do bem dizer o sintoma. O furor sanandi contemporâneo traduzido pelas concepções de cura localizados em aparatos cerebrais ou comportamentais, não leva em conta esta dimensão da experiência clínica. Desta maneira, percebe-se que a psiquiatria clássica e muitas psicoterapias, tentadas pelo furor sanandi de cura acelerada e pela sedução da indústria farmacêutica, buscam a suspensão do sintoma a qualquer custo. No entanto, a psicanálise previne que onde há sintoma, há sujeito. Como ressalta Miller (1997, p.221) "na análise, contudo, as questões técnicas são éticas, por um motivo muito preciso: nela nos dirigimos ao sujeito. A categoria do sujeito não é técnica, e sim, ética". Ora, como se curar daquilo que lhe é mais familiar? Desde os primórdios da psicanálise Freud procurou desarticular a psicanálise do discurso do mestre ao propor a associação-livre como o único princípio da análise, fazendo com que sua técnica se afastasse de uma cura sintomática pautandose pelo atravessamento da fantasia fundamental, tal como nos propõe Lacan.

\section{Considerações finais}

Diante de todas estas considerações, percebe-se que em nossa sociedade atual imediatista, os modelos psicoterápicos clássicos e emergentes atuam de maneira inconteste conforme o modelo da mercantilização: trata-se de extinguir o sintoma e o sujeito a qualquer custo. É o que atestam Jacques-Alain Miller e Jean-Claude Milner (2006, p. 24) ao afirmarem que atualmente, os modelos de avaliação psicológica sustentados pelas leis estatais prevalecem "do pragmatismo de bom grado, apresenta-se como a busca de uma eficiência máxima". E isso, é claro, eleva o "a qualquer custo" à classe de "menor custo". Seguindo a proposta desses autores, percebemos que a eficiência, avaliativa ou terapêutica é, em nosso tempo, síncrona a um posicionamento cientificista que estabelece a direção do tratamento em função de determinantes da esfera social e econômica. Ora, como não ler isto nas propostas de políticas públicas de saúde mental que estabelecem como meta primordial a reabilitação psicossocial? Como não questionar o sentido desta 
reabilitação quando o sintoma não é índice de déficit psíquico, mas antes, um problema colocado por um sujeito e que deve ser clinicado?

Este cenário atual mostra-se animador para a indústria de medicalização do psiquismo, cada dia mais respaldada pelo prestígio cientificista das neurociências, porém o que não podemos perder de vista, são as palavras de Freud em O mal-estar na civilização (1929 [1969]): quanto mais intensa a exigência de exercício da vigilância e da prevenção na civilização, numa relação de proporcionalidade direta, maior será o mal-estar oriundo de nossas renúncias. Em outras palavras, não haveria problemas caso este exercício de cidadania pautada e guiada pela normatização social nos garantisse realmente a felicidade. O problema crucial, ignorado pelos múltiplos defensores da pedagogia social é o preço que o sujeito paga por estas renúncias. Em nome de um ideal de cidadania - planejado por nosso Estado-Estratégia, mas extraída, acima de tudo, do pacífico pacto entre suas práticas e políticas demográficas, epidemiológicas e estatísticas - o sujeito do século XXI mascara, sob a faceta inofensiva do "pacato cidadão", seu sintoma, ou seja, aquilo precisamente que não entra na conta deste balanço contábil. A partir do momento em que entramos na conta, somos parte contada responsáveis por nossos direitos e deveres. Não é exclusividade de nossos dias o triunfo desta perspectiva normativa no campo da saúde uma vez que assistimos, desde o século XIX com os avanços alcançados pela biotecnologia, a uma tentativa de cientificização do fenômeno social, caracterizada pela assunção de uma civilização referenciada pela quantificação do típico em detrimento do único.

\section{Referências}

CANGUILHEM, G. O normal e o patológico. 6. ed. Rio de Janeiro: Forense Universitária, 2009.

FREUD, S. (1900). A interpretação de sonhos. In: Edição Standard das Obras Psicológicas Completas de Sigmund Freud. Vol. IV e V. Rio de Janeiro: I mago, 1996. (1914). A história do movimento psicanalítico. In:

Édição Standard das Obras Psicológicas Completas de Sigmund Freud. Vol. XIV. Rio de Janeiro: I mago, 1996, p. 13-82.

(1915a). Repressão. In:

Edição Standard das

Obras Psicológicas Completas de Sigmund Freud. Vol. XIV. Rio de Janeiro: Imago, 1996, p.165-182.

(1915b). Observações sobre o amor transferencial (Novas Recomendações sobre a Técnica da Psicanálise III). In:

Edição Standard das Obras Psicológicas Completas de Sigmund Freud. Vol. XII. Rio de Janeiro: Imago, 1996, p.207-223. 
. (1916-1917a). O sentido dos sintomas. In:

Edição

Standard das Obras Psicológicas Completas de Sígmund Freud. Vol. XVI. Rio de Janeiro: I mago, 1996, p. 305-322.

. (1916-1917b). Os caminhos da formação dos sintomas.

In: ___ Edição Standard das Obras Psicológicas Completas de Sigmund Freud. Vol. XVI. Rio de Janeiro: Imago, 1996, p. 419439.

(1929). O mal-estar na civilização. In:

Edição

Standard das Obras Psicológicas Completas de Sigmund Freud. Vol. XXI. Rio de Janeiro: I mago, 1996, p. 75-171.

GARCIA-ROZA, L. A. Freud e o inconsciente. 20.ed. Rio de Janeio: J orge Zahar, 2004.

KAPLAN, H. I.; SADOCK, B. J. Compêndio de psiquiatria. 2. ed. Porto Alegre: Artes Médicas, 1990.

LACAN, J. (1972-73) O Seminário, livro 20: mais ainda. 2. ed. Rio de Janeiro: J orge Zahar, 1985.

(1969-70). O Seminário, livro 17: o avesso da psicanálise. 1 ed. Rio de Janeiro: Jorge Zahar, 1992.

. (1965). A ciência e a verdade. In _----- Escritos. Rio de

Janeiro: Jorge Zahar, 1998, p.869-892.

LAURENT. E. O delírio da normalidade. In: _-_Lucuras, sintomas e fantasias na vida cotidiana. Belo Horizonte: Scriptum, 2011, p. 45-56.

MILLER, J. A. Discurso do método psicanalítico. In:

elucidado. Rio de Janeiro: Jorge Zahar, 1997, p. $221-\overline{2} 2 \overline{9}$.

Lacan

A era do homem sem qualidades. Opção lacaniana online,

n. $\quad 1, \quad 2005.2$ Disponível em:

<http://www.opcaolacaniana.com.br/antigos/n1/texto.asp >. Acesso em: 13 jun. 2010.

MILLER, J. A.; MILNER, J. C. Você quer mesmo ser avaliado?. São Paulo: Manole, 2006.

NASIO, J. D. Como trabalha um psicanalista?. Rio de Janeiro: J orge Zahar, 1999.

PIMENTA, A. C.; FERREIRA, R. A. O sintoma na medicina e na psicanálise - notas preliminares. Revista Médica de Minas Gerais, Belo Horizonte, 2003, v. 3, p. 221-228. Disponível em: <http://veterinariosnodiva.com. br/books/9-O-SINTOMA-NA-

MEDICINA-E-NA-PSICANALISE. pdf>. Acesso em: 29 set. 2010.

QUINET, A. A descoberta do inconsciente. Rio de Janeiro: Jorge Zahar, 2000.

SVOLOS, T. Introduzindo o sintoma. Opção lacaniana online. n. 1, $2005 . \quad$ Disponível em: <http://www.opcaolacaniana.com.br/antigos/n1/pdf/artigos/TSintom a.pdf>. Acesso em: 13 jun. 2010. 
Tiago I wasawa Neves, Aryane Martins Lopes, Thaiz Calais Bertges Moraes Reintroduzindo o sintoma: a psicanálise como obstáculo à cientificização do

tratamento psíquico

\section{Endereços para correspondência:}

\section{Tiago I wasawa Neves}

Avenida J uvêncio Arruda, 795, Bodocongó, CEP 58429-140, Campina Grande, PB, Brasil

Endereço eletrônico: tiagoiwasawa@yahoo.com.br

Aryane Martins Lopes

Rua Ester, 819, Canaã, CEP 35164-160, Ipatinga, MG, Brasil

Endereço eletrônico: aryanemartinslopes@yahoo.com.br

Thaiz Calais Bertges Moraes

Rua J equitibá, 401, Horto, CEP 35160-000, Ipatinga, MG, Brasil

Endereço eletrônico: thaizcalais@hotmail.com

Recebido em: 29/06/2011

Reformulado em: 15/02/2012

Aceito para publicação em: 13/03/2012

Acompanhamento do processo editorial: Deise Mancebo

\section{Notas}

* Professor Assistente da Universidade Federal de Campina Grande - UFCG, Campina Grande, Paraíba, Brasil. Mestre em Psicologia pela Universidade Federal de Minas Gerais (UFMG).

** Psicóloga, pós graduanda em Clínica Psicanalítica na Contemporaneidade Unileste-MG. Terapeuta Comunitária (Curso Pró-Reitoria de Extensão da UFC).

*** Psicóloga - Faculdade Pitágoras - Campus Vale do Aço.

1 Miller e Milner (2006) afirmam que o paradigma problema-solução é um dos pilares que determinam o sentido do sofrimento psíquico no registro da saúde mental na contemporaneidade. "Começa-se por estabelecer que há um problema; começa-se levantando-o. Por quê? Porque surge uma queixa na sociedade. É inútil tentar saber se essa queixa é ou não fundamentada, se ela é maciça; ela se estabelece como se fosse uma axioma. Ora, quando um problema se coloca na sociedade, demanda-se aos políticos encontrar uma solução. Tal é o paradigma das relações entre os políticos e a sociedade no universo moderno" (p.3). 